\title{
Attendance to Non-communicable Disease Screening Services and Its Associated Factors among Rural Adults in Dimbulagala, Sri Lanka
}

\author{
Dehiwattage Eroma Gayani Fernando ${ }^{1}$ and Sumal Nandasena ${ }^{2}$ \\ 1. Ministry of Health, Nutrition and Indigenous Medicine, Colombo 01000, Sri Lanka \\ 2. National Institute of Health Sciences, Kaluthara 12000, Sri Lanka
}

\begin{abstract}
Background: Non-Communicable Disease (NCD) incidence continues to increase globally causing high morbidity and mortality. Despite being a major health problem in Sri Lanka, low attendance is reported in free government NCD screening services (i.e., Healthy life style center (HLC) and the Well Women Clinic (WWC)). This community based study aims to assess the attendance in NCD screening services, and its associated factors among 35 to 65 year adults in Dimbulagala Medical Officer of Health $(\mathrm{MOH})$ area in Sri Lanka. Methods: The community based cross sectional study interviewed resident adults of the Dimbulagala MOH area in the North Central Province of Sri Lanka during August 2016. The sample of residents $(n=575)$ were selected from 30 housing clusters representing the study setting and an interviewer administered questionnaire was used among residents of both genders to ascertain the data on attendance and factors associated with attendance to NCD screening clinics. Results: Five hundred and thirty-seven $(n=537)$ questionnaires were successfully administered with a response rate of 93\%. The mean age of the study population was 46.5 (Standard Deviation $(\mathrm{SD})=8.75$ ) years. Majority $(83.2 \%)$ of the study population had scored more than the middle value (i.e., 20) of the knowledge score and only $37.8 \%$ individuals have ever attended an NCD screening clinic. The "gender" and "awareness on HLC/WWC" are the most important factors determining the attendance to a screening clinic. Conclusions and recommendations: There is a gap between the respondents' NCD screening knowledge and attendance to NCD screening services. Main factors associated with attending NCD screening clinics were gender of the study participants and their awareness of HLC or WWC.
\end{abstract}

Key words: NCD, attendance to NCD screening, HLC, WWC.

$\begin{array}{ll}\text { Abbreviations } \\ \text { CVD } & \begin{array}{l}\text { Cardiovascular diseases } \\ \text { General Certificate in Education (Ordinary }\end{array} \\ \text { GCE (O/L) } & \begin{array}{l}\text { Level) } \\ \text { Grama Sewa Niladari }\end{array} \\ \text { GN } & \text { Healthy life style center } \\ \text { HLC } & \text { Ischemic heart disease } \\ \text { IHD } & \text { Medical Officer of Health } \\ \text { MOH } & \text { Non Communicable Disease } \\ \text { NCD } & \text { South-East Asia region } \\ \text { SEAR } & \text { Standard Deviation } \\ \text { SD } & \text { World Health Organization } \\ \text { WHO } & \text { Well Women Clinic } \\ \text { WWC } & \end{array}$

Corresponding author: Dehiwattage Eroma Gayani Fernando, Dr., postgraduate MD trainee, research fields: non communicable diseases.

\section{Introduction}

NCDs are defined as "diseases persistent for a lengthy duration with generally slow progression” [1]. NCDs are the major cause of adult mortality and morbidity worldwide [2] and the number of deaths resulted by NCDs account for 40 million per annum, out of which 31 million deaths occur in low and middle income countries [3]. Cardiovascular diseases (CVD) account for most NCD deaths (17.7 million people annually), followed by cancers (8.8 million), respiratory diseases (3.9 million), and diabetes (1.6 million).

Although there are many types of NCDs, the main types are CVDs (e.g., heart attacks and stroke), chronic respiratory diseases (e.g., asthma and chronic 
obstructed pulmonary disease), diabetes and cancer [4]. These four groups of diseases account for $81 \%$ of total NCD deaths [3]. Premature deaths are a major consideration when evaluating the implications of NCDs. Each year, 17 million deaths occur due to NCD before the age of 70 , and $87 \%$ of these "premature" deaths occur in low and middle-income countries [3]. NCDs are a major cause of preventable disability worldwide [5] and could lead to adverse complications including amputations, blindness, impairments in mobility and speech [6]. These complications may lead to reduction in productivity and economic loss, increasing the demand on social and health systems.

The NCD burden in Sri Lanka witnessed an increasing trend during the last few years and has presently become the leading cause of mortality, morbidity and disability in Sri Lanka [7]. Analysis in Sri Lanka's mortality data during 1999-2003 shows that age standardized mortality rates for all NCDs are 20\%-50\% higher in Sri Lanka compared to developed countries [8]. Government hospital statistics indicate that in 2008, 71\% of all annual deaths in Sri Lanka were due to chronic NCDs [7]. In fact, CVD, diabetes, cancer and chronic respiratory diseases account for $29.6 \%, 9.4 \%, 3.9 \%$ and $8.5 \%$ deaths respectively while ischemic heart diseases (IHD) were the leading cause of hospital deaths from 2006-2014 [22]. Diabetes prevalence in Sri Lanka has projected diabetes to be at $13.9 \%$ by year 2030 [9].

An increasing trend in NCD has resulted in substantial cost for clinical management, loss of productivity and social issues. The government of Sri Lanka has identified the importance of early detection of diseases by establishing screening programs mainly through HLC and WWC at community level. The concept of WWCs was established in 1996 with the introduction of screening women for selected NCD including reproductive organ malignancy [10]. HLC was introduced in the latter part of 2011 [11] for screening adults of both gender in the age group of 40 to 65 years. Irrespective of substantial resource allocation and the positive impact of screening, WWC and HLC services are underutilized by the targeted population in Sri Lanka. Several quantitative and qualitative studies have been carried out to determine factors contributing to the low uptake of screening services in different communities [12, 13], even though such studies are limited in Sri Lanka. However, knowledge on factors affecting participation in NCD screening services is essential to design and implement programs to encourage the people to seek NCD screening and reduce the overall disease burden.

The main objective of this study was to assess the factors associated in attendance to screening services provided by the Ministry of Health, Sri Lanka at a community level in the Dimbulagala $\mathrm{MOH}$ area in North Central Province of Sri Lanka.

\section{Methods}

\subsection{Study Setting and Study Population}

This study was conducted in Dimbulagala $\mathrm{MOH}$ area, located in the Polonnaruwa district in the North Central Province of Sri Lanka (Fig. 1). The study area comprised a total population of 79,661, out of which 28,127 met the eligibility criteria for the present study (i.e., 35 to 65 years of age) [14]. The area is further divided into 56 Grama Sewa Niladari (GN) divisions, the smallest administrative division in the study area.

\subsection{Sampling Method}

Thirty housing clusters were selected by probability proportionate to the size of the number of households in each GN division and only one eligible person was recruited from a household. If more than one eligible person was present at a household, the study participant was selected randomly using the "Kish selection table” [15] and was estimated to enroll 575 adults as study participants [16].

\subsection{Data Collection Procedures}

A pre-tested interviewer administered questionnaire 
was used to collect data in Sinhala and Tamil languages; the native languages of the study participants. The questionnaire consisted of socio-demographic characteristics of respondents, knowledge on NCD screening, awareness on screening services available and factors influencing attendance to NCD screening services among the targeted population. Four aspects of awareness in diabetes, hypertension and CVDs (i.e., knowledge on screening methods for early identification, the availability of testing, complications and importance of periodic screening) were assessed. Data collection was done by four trained research assistants.

\subsection{Data Analysis}

The socio-demographic characteristics were reported as frequencies and percentages, and categorized appropriately. A knowledge score was developed for all the diseases together and answers to all the questions were presented with frequencies and percentages. The total score was taken by adding all correct answers and dividing by the total number of questions and then multiplying by hundred for each participant. The population was divided into two groups as (1) poor knowledge and (2) good knowledge based on the median value of the distribution of reported cumulative scores of the study population. Attendance to the clinic was compared with socio demographic characteristics and other associated factors (i.e., distance, positive family history, awareness of services, method of awareness, etc.). Multivariate analysis was used to identify the most important variable/s among significant variables in univariate analysis.

\subsection{Ethical Concerns}

The study was approved by the Ethics Review Committee of the National Institute of Health Sciences, Kalutara, Sri Lanka prior to conducting the study. At the initial contact with the potential participants, an information sheet was provided and a written consent was obtained.

\subsection{Results}

With the response rate of 93\%, 537 questionnaires were administered. The mean age of the respondents was 46 years $(\mathrm{SD}=8.75)$ and majority were females (289, 53.8\%) and Buddhists (535, 99.6\%). The ethnicity of all respondents was Sinhalese and approximately $53 \%$ of respondents had completed at least 10 years of school education. The basic socio demographic characteristics of the sample are summarized in Table 1.

\subsection{Knowledge on NCD Screening}

Majority (83.2\%) of the study population had scored more than the middle value (i.e., 20) of the knowledge score. Majority of the females (53.8\%) had a good knowledge while the males had only $46.2 \%$ (Table 2).

\subsection{Attendance to Free Government NCD Screening Clinics}

Out of the total study population, majority (62.2\%, $n$ = 334) have never attended any NCD screening clinic while the rest have attended (203, 37.8\%).

\subsection{Awareness on Free Government Screening Services for NCD}

The study results did not indicate a clear association between awareness and attendance to provided facilities. For example, less than $40 \%$ of the respondents were aware of HLC, out of which only 47.7\% had attended a NCD screening clinic in their lifetime. Similarly, $66.9 \%$ of the total female respondents were aware of WWCs and $75.1 \%$ of it had attended. Further, $44.6 \%$ were aware of Pap smear screening at WWC but nearly $60 \%$ of the sample females had never undergone the test as a method of screening for cervical cancer and not even simple measures like regular self-breast examinations were practiced apart from 25\% of the female respondents. 
Attendance to Non-communicable Disease Screening Services and Its Associated Factors among Rural 51 Adults in Dimbulagala, Sri Lanka

Table 1 Selected socio-demographic characteristics of the study population.

\begin{tabular}{|c|c|c|}
\hline Characteristic & Frequency $(n=537)$ & Percentage (\%) \\
\hline \multicolumn{3}{|l|}{ Age } \\
\hline$<50$ years & 351 & 65.4 \\
\hline$>50$ years & 186 & 34.6 \\
\hline \multicolumn{3}{|l|}{ Gender } \\
\hline Male & 248 & 46.2 \\
\hline Female & 289 & 53.8 \\
\hline \multicolumn{3}{|l|}{ Ethnicity } \\
\hline Sinhalese & 537 & 100.0 \\
\hline Non Sinhalese* & 0 & 0.0 \\
\hline \multicolumn{3}{|l|}{ Religion } \\
\hline Buddhist & 535 & 99.6 \\
\hline Non Buddhist** & 2 & 0.4 \\
\hline \multicolumn{3}{|l|}{ Marital status } \\
\hline Currently married & 480 & 89.4 \\
\hline Other*** & 57 & 10.6 \\
\hline \multicolumn{3}{|l|}{ Educational level } \\
\hline No schooling /Up to Grade 10 & 283 & 52.7 \\
\hline Passed GCE (O/L) \& above & 254 & 47.3 \\
\hline \multicolumn{3}{|l|}{ Educational level of your spouse } \\
\hline No schooling /Up to Grade 10 & 278 & 52.0 \\
\hline Passed GCE (O/L) \& above & 259 & 48.0 \\
\hline \multicolumn{3}{|l|}{ Employment status } \\
\hline Currently employed & 355 & 66.1 \\
\hline Currently unemployed & 182 & 33.9 \\
\hline \multicolumn{3}{|l|}{ Employment status of your spouse } \\
\hline Currently employed & 347 & 65.0 \\
\hline Currently unemployed & 190 & 35.0 \\
\hline \multicolumn{3}{|l|}{ Income per month } \\
\hline Rs. 30,000 or less & 292 & 54.4 \\
\hline Above Rs. 30,000 & 245 & 45.6 \\
\hline \multicolumn{3}{|l|}{ Family income per month } \\
\hline Rs. 30,000 or less & 340 & 63.4 \\
\hline Above Rs. 30,000 & 197 & 36.6 \\
\hline Total & 537 & 100.0 \\
\hline
\end{tabular}

* Non Sinhalese = Sri Lankan Tamil, Indian Tamil, Sri Lankan Moor, Burgher, Malay.

** Non Buddhist $=$ Hindu, Islam, Roman Catholic, Other Christian and other.

*** Other $=$ separated/divorced, widowed, single.

$\mathrm{O} / \mathrm{L}=$ Ordinary level.

Table 2 Distribution of knowledge score on NCD screening in Dimbulagala MOH area by gender.

\begin{tabular}{llll}
\hline \multirow{2}{*}{ Knowledge groups } & \multicolumn{2}{c}{ Gender } \\
\cline { 2 - 4 } & $\begin{array}{l}\text { Male } \\
n(\%)\end{array}$ & $\begin{array}{l}\text { Female } \\
n(\%)\end{array}$ & $\begin{array}{l}\text { Total } \\
n(\%)\end{array}$ \\
\hline Knowledge $<50 \%$ & $50(55.6 \%)$ & $40(44.4 \%)$ & $90(100.0 \%)$ \\
Knowledge $50 \%$ or more & $198(44.3 \%)$ & $249(55.7 \%)$ & $447(100.0 \%)$ \\
Total & $248(46.2 \%)$ & $289(53.8 \%)$ & $537(100.0 \%)$ \\
\hline
\end{tabular}


The total level of awareness was lesser in males compared to women.

\subsection{Factors Associated with Attendance to Screening} Clinics

Association of selected factors and attending to NCD screening clinics (WWC, HLC) are summarized in Table 3.

There was a significant association $(p<0.05)$ between attendance to clinics with age, gender, marital status, educational level and employment status.

The multivariate analysis was performed on variables found to have a significant effect in univariate analysis (Table 4). The binary logistic

Table 3 Association between attendance and socio demographic characteristics.

\begin{tabular}{|c|c|c|c|c|}
\hline \multirow[t]{2}{*}{ Characteristic } & \multicolumn{2}{|c|}{ Attendance } & \multirow[t]{2}{*}{ Total $(n \%)$} & \multirow[t]{2}{*}{ Significance } \\
\hline & Yes & No & & \\
\hline \multicolumn{5}{|l|}{ Age } \\
\hline$<50$ years & 157 (77.3) & $194(58.1)$ & $351(65.4)$ & \\
\hline$>50$ years & $46(22.7)$ & 140 (41.9) & $186(34.6)$ & $p<0.001$ \\
\hline \multicolumn{5}{|l|}{ Gender } \\
\hline Male & $35(17.2)$ & $213(63.8)$ & $248(46.2)$ & \\
\hline Female & $168(82.8)$ & $121(36.2)$ & $289(53.8)$ & $p<0.001$ \\
\hline \multicolumn{5}{|l|}{ Marital status } \\
\hline Currently married & $174(85.7)$ & $306(91.6)$ & $480(89.4)$ & \\
\hline Other* & $29(14.3)$ & $28(8.4)$ & $57(10.6)$ & $p=0.031$ \\
\hline \multicolumn{5}{|l|}{ Educational level } \\
\hline No schooling /Up to grade 10 & $73(36.0)$ & 210 (62.9) & $283(52.7)$ & \\
\hline Passed GCE (O/L) \& above & $130(64.0)$ & $124(37.1)$ & $254(47.3)$ & $p<0.001$ \\
\hline \multicolumn{5}{|l|}{ Employment status } \\
\hline Currently employed & $88(43.3)$ & 267 (79.9) & $355(66.1)$ & \\
\hline Currently unemployed & $115(56.7)$ & $67(20.1)$ & $182(33.9)$ & $p<0.001$ \\
\hline \multicolumn{5}{|l|}{ Income per month } \\
\hline 30,000 or less & 85 (41.9) & $207(62.7)$ & $292(54.4)$ & \\
\hline Above 30,000 & $118(58.1)$ & $127(38.0)$ & $245(45.6)$ & $p=0.867$ \\
\hline \multicolumn{5}{|l|}{ Family income per month } \\
\hline 30,000 or less & $135(66.5)$ & 206 (61.7) & 341 (63.5) & \\
\hline Above 30,000 & 68 (33.5) & $128(38.3)$ & 196 (36.5) & $p=0.260$ \\
\hline Total & 203 (100) & 334 (100) & 537 (100) & \\
\hline
\end{tabular}

* Other = separated/divorced, widowed, single.

$\mathrm{O} / \mathrm{L}=$ Ordinary level.

Table 4 Multivariate analysis to determine association with attendance to clinic.

\begin{tabular}{lllll}
\hline \multirow{2}{*}{ Variable } & \multirow{2}{*}{ B coefficient } & \multicolumn{2}{c}{ 95\% confident interval } & $p$ value \\
\cline { 3 - 5 } & & Lower limit & Upper limit & 0.012 \\
Age $\leq 50$ & 1.926 & 1.153 & 3.218 & $<0.001$ \\
Gender & 0.137 & 0.0736 & 0.246 & 0.621 \\
Marital status & 0.833 & 0.403 & 1.720 & 0.007 \\
Level of education & 0.529 & 0.332 & 0.842 & 0.004 \\
Employment status & 0.448 & 0.260 & 0.772 & 0.934 \\
Overall knowledge & 0.972 & 0.500 & 1.892 & $<0.001$ \\
Heard about HLC & 6.981 & 4.271 & 11.409 & 0.058 \\
Distance to HLC & 0.585 & 0.336 & 1.018 & 2.237 \\
Positive family history & 2.237 & 1.385 & 3.612 & 0.521 \\
Constant & 0.706 & &
\end{tabular}

HLC = Healthy Life Style Center. 
regression showed "Gender" and "heard about HLC" as the most important factors which determines the attendance to a screening clinic.

\section{Discussion}

\subsection{Main Findings}

The present study gives important information on knowledge among the study population pertaining to NCD screening and only $16.75 \%$ possessed the knowledge score to be less than the middle value of the total score. Nevertheless, there was a significant association ( $p<0.05$ ) of having an overall good knowledge on NCD screening and attendance to NCD screening clinics. Further, awareness itself does not assure the attendance to clinics. The present study results show that the overall number of women attending WWCs was comparatively lesser compared to the percentage of women who were aware of the clinics. Perhaps, there are many other factors affecting the attendance. Hence, it is important to understand these factors as well when concluding the findings.

Socio demographic factors (age, gender, marital status, educational level and employment), heard about the clinic, health worker being the informant, person deciding the financial management of the family, positive family history of NCD and distance to HLC were associated factors relating to attending a screening clinic. Out of which, "gender" and "heard about HLC" were the most important factors which determined the attendance to a screening clinic. The findings of this study should be used to design a tailor-made awareness program targeting the community and addressing the issues on barriers in attending the services provided.

\subsection{Knowledge on NCD Screening among the Study Population}

In this study, the knowledge of participants was assessed under three broad sections as: knowledge on diabetes, knowledge on hypertension and knowledge on CVDs. However, the present study indicates that 83.25\% ( $n=447)$ participants had an overall good level of knowledge while $16.7 \%(n=90)$ of the study population had an overall poor level of knowledge. The majority of females (55.7\%) had an overall good knowledge on NCD while the male population scored only $44.3 \%$.

A reason for higher knowledge could be due to the high literacy in Sri Lanka and the effective health education provided by the health sector. A study carried out among users and non-users of WWC in Dompe, Sri Lanka on knowledge of NCD screening reported that clinic users had a better knowledge compared to non-users $(p<0.001)$ [17]. This may be due to awareness created through the health sector, electronic media and their own family experience. A previous cross sectional study conducted among grade 10 students in the district of Mannar, Sri Lanka with regard to knowledge on NCDs, revealed an overall good level of knowledge with $90 \%$ of the population being aware of NCD, $79 \%$ of the population identifying common NCDs, $84 \%$ of the population having a good knowledge on complications and 78\% of the population having awareness on risk factors [18]. Similarly, a study in Seychelles reported that a higher proportion of the population had basic knowledge on hypertension compared to specific knowledge and 96\% were aware of the risk of hypertension on heart disease. However, this value is comparatively higher than the present study. Further, studies conducted by Kusuma, Gupta \& Pandav [17] and Egan et al. [19] reported that $94 \%$ and $96 \%$ of their study populations knew the risk of heart diseases, respectively.

The level of knowledge among females was more than that of males in this study. Similarly, a Mongolian study reported that housewives are the most informed on blood pressure from the total population [20]. Due to the well-integrated maternal and child health programs at the primary health care level in the Sri Lankan context, females have a better 
attachment with the healthcare system and the primary healthcare worker. Probably they receive health education more often as they are in contact with the health system more than their male counterparts. As these clinics are mostly conducted during the morning hours; majority of the males are not able to attend them. It is interesting to explore the reason for not disseminating knowledge from females to males; perhaps current policies, programs should be targeting this issue.

\subsection{Awareness on NCD Screening Services among the Study Population}

The study shows that awareness on HLCs among respondents is considerably poor ( $n=214,39.9 \%$ ) and reported a gender difference (females $=46.4 \%$ and males $=32.3 \%$ ). About $67 \%$ of the female population were aware of WWC; a higher proportion when compared to awareness on HLCs. A study from Southern Province of Sri Lanka reported similar results on WWC, where only $66 \%$ of the female population was aware of WWC [21] indicating it is a wide spread issue in Sri Lanka. The study shows that healthcare workers are the largest source of information with regards to creating awareness followed by television. HLCs are also responsible for promoting awareness on WWCs among the study population and vice versa. Previous studies conducted in Sri Lanka have also shown primary healthcare workers and television as critical sources of information in the promotion of healthcare [22, 23]. Thus, it is necessary to recognize the role of the primary healthcare workers and television as powerful tools of health promotion and engage them in an optimal manner in improving NCD prevention interventions in Dimbulagala $\mathrm{MOH}$ area and elsewhere in the country.

The present study indicates that the best mode of information dissemination is by a healthcare worker during home visits. In fact, $76.6 \%$ and $77.7 \%$ of respondents stated that they received information on
HLC and WWC, respectively during home visits of the healthcare worker. Thus, the importance of home visits of the healthcare worker in NCD prevention programs is highlighted. It was also noted that females are more likely to benefit from home visits as opposed to males as indicated by the study results; females may stay at home or work from home. Hence, NCD prevention strategies should target the males in a remedial manner.

According to a survey assessing breast cancer screening in Saudi Arabia, 57\% of the respondents performed a self-breast examination but $89 \%$ of women did not undergo clinical breast examinations during the past year [24]. However, the present study indicates that $34.9 \%(n=101)$ have undergone clinical breast examination and 25.6\% $(n=74)$ have undergone self-breast examination in their lifetime. A study done in Kenya indicates that only $12.3 \%$ was screened for cervical cancer [25] and a similar study done in 2014 concludes that the number of participants who were ever screened was 25\% [26]. A study conducted in the Gampaha district, Sri Lanka indicated that only 131 out of 2,000 participants (6.5\%) were ever screened for cervical cancer [6]. Similarly, the present study reported $26.6 \%$ ( $n=77$ ) women were practicing in screening by Pap smear for cervical cancer.

The present study indicates that half of the study population ( $n=293,54.6 \%$ ) had practiced measuring blood pressure as a method of early detection for hypertension. However, a study in Kathmandu Nepal revealed that, out of 789 respondents only half had their blood pressure measured [27]. Although, most of the study population of the present study had measured blood pressure with a slightly higher proportion among the females, it could be argued that the entire study population should have undergone as its one of the basic tests.

\subsection{Selected Factors Associated with Attendance to NCD Screening Clinics}

When considering NCDs, adherence to a healthy 
life style and early detection by screening is the main mode of prevention and reducing complications. In the present study, 37.8\% ( $n=203$ ) of the study population have used an NCD screening clinic at least once in their life time. The attendance needs to be further improved in view of minimizing the unhealthy effects of NCD.

Even though the common assumption was that a respondent's income and family income had a direct impact on attending NCD screening clinics, it was evident that the above was not one of the significantly associated with attendance, but age, sex, marital status, level of education and employment had a significant association $(p<0.05)$ with the attendance to NCD screening clinics. A study conducted in Italy [28] indicated that socio-economic factors were shown to be strongly related to the use of preventive services. Another study concluded [29] that a robust relationship existed between being married and the educational level of the individuals. Also, it was found in that study, that $52 \%$ have used screening services within the last 12 months, while $48 \%$ did not. A study conducted in Sri Lanka on the implication of screening found that education and employment to be significantly associated with each other $(p=0.038)$ [21].

The present study indicates a significant association $(p<0.05)$ between overall knowledge on NCD screening and attendance to the NCD screening clinics, where respondents with a good knowledge (40.9\%) had more attendance than respondents with poor knowledge (20\%). A study carried out in Nnewi, Nigeria revealed that even though the knowledge is high, the attendance is poor [30].

There was a clear disparity between awareness of the clinic and attendance. The present study reported 47.6\% and $75.1 \%$, for attending HLC and WWC respectively. In another study conducted in Sri Lanka revealed that $66 \%$ of the total samples were aware of WWC but only $24 \%$ of the eligible sample had ever attended [21]. This clearly indicates that awareness itself does not confirm the attendance to clinic, perhaps various other factors may influence the attendance. Thus, adequate awareness on the services provided by the government health care sector is required to improve the attendance of each and every targeted person. The study shows that there is a strong association between the healthcare worker being the informant and attending the clinic. This could be due to the healthcare worker being able to build a strong rapport with the community.

The present study shows a significant association between distance and attendance to HLC but there was no significant association between distance and attendance to WWC. However, in both instances, it was shown that the highest proportion was attended when the distance was less than $6 \mathrm{~km}$. Similarly, a previous cross sectional study identified that most of the WWC users ( $n=137,35.9 \%)$ were residents within $2 \mathrm{~km}$ from the clinic [21]. Also, there was no statistical significance between NCD clinic attendance and the person making the decision about the healthcare of the family and healthcare of the respondent $(p>0.05)$. While the person deciding the financial management of the family was statistically significant $(p<0.05)$ in attendance to any NCD screening clinic.

\subsection{Limitations of the Study}

Present study is a community based study and the data was extracted from the households furnishing a "snap shot" experience of the population at a specified time period, thus the study may have methodological limitations inherent to cross sectional studies. Specifically, the temporal relationship cannot be evaluated. As an example, the knowledge ascertained may or may not be due to their attendance to the clinics.

The study was conducted in the Dimbulagla $\mathrm{MOH}$ area. Dimbulagala area is located bordering to the Eastern Province and majority of the population has an agricultural background. While the study sample 
represents the Dimbulagala $\mathrm{MOH}$ area, caution should be taken in applying the study findings to the rest of the districts in Sri Lanka as they are likely to vary in a range of factors including the livelihoods and income levels of the populations.

Data were collected by an interviewer administered, structured questionnaire conducted by many data collectors. Therefore, the level of understanding of the content of the questions may differ from person to person and could lead to some interviewer bias. This was minimized by rigorous training provided to the data collectors prior to administering the questionnaire. The questionnaire used in the present study was developed by the principal investigator and it is not a validated questionnaire used in the same socio-cultural setting in previous occasions. However, measures were taken to cover all the important components pertaining to NCDs to achieve the objectives of the study and pre-test the study instrument in similar geographical contexts. Further, the study instrument was face and content validated with experts in the field.

The overall knowledge level of respondents on NCD screening was assessed based on the knowledge score developed based on the set of questions and marks were allocated equally for each question. Certain questions may have specific significance to the population based on health patterns which could not have been found out prior to the study. However, there may be certain questions where the importance may vary from the others. Further, the knowledge score was not validated. Hence, the knowledge score may not accurately reflect the knowledge level of the study population.

Some questions in the questionnaire required answers with recalling the information. This would have led to recall bias. However, health related behaviors of a person are remarkable, thus, it is expected for the recall bias to be minimum.

\section{Conclusion}

Knowledge among the study population pertaining to NCD screening, only $16.7 \%$ possessed the knowledge score to be less than the middle value of the total score. There was a significant association ( $p$ $<0.05$ ) of having an overall good knowledge on NCD screening and attendance to NCD screening clinics. Socio demographic factors (age, gender, marital status, educational level, employment), heard about the clinic, health worker being the informant, person deciding the financial management of the family, positive family history of NCD and distance to HLC were associated factors relating to attending a screening clinic. Out of these, "Gender" and "heard about HLC" were the most important factors which determined the attendance to a screening clinic. This study is executed timely to explore reasons for poor attendance by the target group, in order to promote the uptake of free NCD screening services in Sri Lanka. In addition, this will provide useful information to the health sector to formulate effective strategies and programs that will address factors influencing the attendance to free NCD screening services provided by the government to prevent the alarming morbidity and mortality rates of NCD in Sri Lanka. The study has demonstrated low level of attendance to free NCD screening services and some determinants that need to be taken into account when providing the services.

\section{Acknowledgment}

With the greatest pleasure and gratitude, I would like to recognize and appreciate those who assisted me in numerous ways to make this study a success. First, I appreciate the study participants who devoted their time and efforts during the data collection process. Next, I highly appreciate the Board of Studies in Community Medicine, Post Graduate Institute of Medicine, University of Colombo, Sri Lanka for giving me the opportunity to conduct this study. Further, I appreciate the National Institute of Health Sciences, Kalutara, Sri Lanka for granting ethical clearance for the study. Special appreciation goes to 

Adults in Dimbulagala, Sri Lanka

the Regional Director of Health Services, District of Polonnaruwa, Sri Lanka for granting the administrative clearance for the study. Further, I wish to thank all the data collectors acquired locally, for their dedication in timely completion of the data collection. Finally, I gratefully acknowledge the guidance and support provided by the co-author.

\section{Declarations}

\section{Ethics Approval \& Consent for Participation}

National Institute of Health Sciences, Kaluthara, Sri Lanka-Ref: NIHS/ERC/16/18

At the initial contact with the potential participants, an information sheet was provided with all necessary information and the opportunity was given to ask questions. Informed written consent was obtained prior to administer the questionnaire. The study did not include any risks, invasive procedure, collection of biological specimens and questioning of socially unacceptable information. The information gathered through the study was considered strictly confidential. Any information relevant to the participants is not presented in the results or any other research related communication. All databases and questionnaires are kept confidential by the principal investigator. Only the principal investigator can access the data base.

\section{Availability of Data and Materials}

The data sets generated and analyzed during the current study are not publicly available but are available for review through the corresponding author on reasonable request due to containing of many other data apart from the data presented in the article.

Competing interests: The authors declare that they have no competing interests.

Funding: The Ministry of Health, Nutrition and Indigenous Medicine, Sri Lanka

Author contributions: ER and SN conceptualized the study. ER supervised the data collection, analyzed and wrote the first draft of manuscript. All authors contributed to the final manuscript and approved its contents.

\section{References}

[1] Strong, K., Wald, N., Miller, A., and Alwan, A. 2005. "Current Concepts in Screening NCD: WHO Consultation Group Report on Methodology of NCD Screening." Journal Med Screen 12 (1): 9-12. http://journals.sagepub.com/doi/abs/10.1258/0969141053 279086 Accessed 15th April 2016.

[2] World Health Organization. 2015. Non-communicable Diseases.

http://www.who.int/mediacentre/factsheets/fs355/en/Acc essed 24th Dec 2016.

[3] World Health Organization. 2015. Non-communicable Diseases.

http://www.who.int/mediacentre/factsheets/fs355/en/Acc essed 25th May 2017.

[4] WHO. 2013. Global Action Plan for the Prevention and Control of NCDs, 2013-2020. Geneva: World Health Organization.

http://www.who.int/nmh/publications/ncd-action-plan/en/ Accessed 12 Sept 2016.

[5] Richards, N. C., Gouda, H. N., Durham, J., Rampatige, R., Rodney, A., and Whittaker, M. 2015. "Disability, Non Communicable Disease and health information.” Bulletin of the WHO 94: 230-2. DOI: http://dx.doi.org/10. 2471/BLT.15.156869Accessed 18th August 2016.

[6] Gamage, D. G. 2009. "Prevalence of Carcinogenic HPV Infection \& Burden of Cervical Cancer Attributable to It in the District of Gampaha.” MSc Community Medicine Dissertation, Post Graduate of Medicine (PGIM), University of Colombo, Sri Lanka.

[7] Medical Statistics Unit, Ministry of Health, Nutrition and Indigenous Medicine, SL. Annual Health Bulletine 2014.

[8] Engelgau, M., Okamoto, K., Navaratne, K. V., and Gopalan, S. 2010. Prevention and Control of Selected Chronic NCDs in Sri Lanka: Policy Options and Action. Washington, DC: World Bank. http://siteresources. worldbank.org/HEALTHNUTRITIONANDPOPULATI ON/Resources/281627-1095698140167/NCDsSriLanka.p dfAccessed 16th July 2016.

[9] Adler, A., Constantine, G. R., Katulanda, P., Mahesh, J. G., Matthews, D. R., McCarthy, M., Seneviratne, R. D. A., Sheriff, R., Wijeratne, S., and Wijesuriys, M. 2008. "Prevalence and Projections of Diabetes and Prediabetes in Adults in Sri Lanka-Sri Lanka Diabetes, Cardiovascular Study.” Diabetic Medicine 25 (9): 1062-9. doi: 10.1111/j.1464-5491.2008.02523.x.

[10] Family Health Bureau. 2007. Annual Report of Family Health Sri Lanka 2006-2007. Colombo: Family Health Bureau. 
[11] Ministry of Health. 2010. “The National Policy \& Strategic Framework for Prevention and Control of Chronic Non-communicable Diseases.” Sri Lanka, Government Publication Bureau. http://203.94.76. 60/NCD/temp/NCD\%20Policy\%20English.pdf Accessed 16th April 2016.

[12] Lin, S. J. 2008. "Factors Influencing the Uptake of Screening Services for Breast and Cervical Cancer in Taiwan." The Journal of the Royal Society for the Promotion of Health 128 (6): 327-34. https://www.ncbi. nlm.nih.gov/pubmed/19058475Accessed 14th June 2016.

[13] Mutyaba, T., Faxelid, E., Mirembe, F., and Weiderpass, E. 2007. "Influences on Uptake of Reproductive Health Services on Nsangi Community of Uganda and Their Implications for Cervical Cancer Screening.” Reproductive Health 4: 4. DOI: 10.1186/1742-4755-4-4.

[14] Department of Census and Statistics knowledgebase. SL. 2013.

http://www.statistics.gov.lk/PopHouSat/CPH2011/index. php?fileName $=$ Polonnaruwa\&gp=Activities $\&$ tpl $=3$ Accessed 18th April 2016.

[15] Goodman, R., and Kish, L. 1950. "Controlled Selection; a Technique in Probability Sampling." Journal of the American Statistical Association 45 (251): 350-72.

[16] Lwanga, S. K., and Lemeshow, S. 1991. Sample Size Determination in Health Studies: A Practical Manual.

[17] Gupta, S. K., Kusuma, Y. S., and Pandav, C. S. 2009. "Knowledge and Perceptions about Hypertension among Neo and Settled Migrant in Delhi, India." CVD Prevention and Control 4: 2119-29. DOI: 10.1016/ j.cvdpc.2008.

[18] Coonghe, P. A. D. 2010. "Knowledge on Common Non-communicable Diseases, Attitudes and Practices Related to Healthy Lifestyles among Grade 10 Students in Mannar District.” MSc Dissertation, Post Graduate of Medicine (PGIM), University of Colombo, Sri Lanka.

[19] Egan, M. B., Lackland, D. T., and Cutler, N. E. 2003. "Awareness, Knowledge and Attitudes of Older Americans about High Blood Pressure, Implications for Health Care Policy, Education and Research.” Archives of Internal Medicine 163: 681-7.

[20] Demaio, A. R., Otgontuya, D., de Courten, M., Bygbjerg, I. C., Enkhtuya, P., Meyrowitsch, D. W., and Oyunbileg, J. 2013. "Hypertension and Hypertension-related Disease in Mongolia; Findings of a National Knowledge, Attitudes and Practices Study."BMC Public Health 13: 194.http://doi.org/10.1186/1471-2458-13-194Accessed 18th April 2016.

[21] Witharana, C., Wijesiriwardhana, P., Jayasekara, K., Kumari, P., and Rodrigo, C. 2015. "Awareness of Female Malignancies among Women and Their Partners in Southern Sri Lanka and Implications for Screening: A
Cross Sectional Study.” BMC Public Health 15: 1179. http://doi.org/10.1186/s12889-015-2531-6 Accessed 4th May 2016.

[22] Vithana, P. V. S. C. 2010. "Breast Cancer Screening Services in the District of Gampaha: Quality and Effectiveness of an Educational Intervention.” MD Thesis, Post Graduate of Medicine (PGIM), University of Colombo, Sri Lanka.

[23] Liyanage, D. T. P. 2002. "Evaluation of Selected Aspects of the National Cervical Screening Programme in Kaluthara District and the Effectiveness of an Educational Intervention.” MD Thesis, Post Graduate of Medicine (PGIM), University of Colombo, Sri Lanka.

[24] El Bcheraoui, C., Basulaiman, M., Wilson, S., Daoud, F., Tuffaha, M., AlMazroa, M. A. et al. 2015. "Breast Cancer Screening in Saudi Arabia: Free but Almost No Takers." PLOS ONE $10 \quad$ (3): e0119051.https://doi.org/10.1371/journal.pone.0119051 Accessed 18th April 2017.

[25] Ichaminya, A. 2015. "Factors Influencing Uptake of Screening Cervical Cancer among Women of Reproductive Age in Vihiga County, Kenya.” MSc Thesis, University of Nairobi, Kenya; http://hdl.handle. net/11295/92926 Accessed 16th June 2016.

[26] Nthiga, A. M. 2014. "Determinants of Cervical Cancer Screening Uptake among Women in Embu County, Kenya.” Thesis, University of Nairobi, Kenya.http://erepository.uonbi.ac.ke/handle/11295/75222 ?show=full Accessed 17th August 2016.

[27] Vaidya, A., Aryal, U. R., andKrettek, A. 2013. "Cardiovascular Health Knowledge, Attitude and Practice/Behaviour in an Urbanising Community of Nepal: a Population-based Cross-sectional Study from Jhaukhel-Duwakot." Health Demographic Surveillance Site. BMJ Open. 3: e002976. DOI: 10.1136/ bmjopen-2013-002976.

[28] Damiani, G., Federico, B., Basso, D., Ronconi, A., Bianchi, C. B. N. A., Anzellotti, G. M., and Ricciardi, W. 2012. "Socioeconomic Disparities in the Uptake of Breast and Cervical Cancer Screening in Italy: A Cross Sectional Study." BMC Public Health 12: 99. doi.org/10.1186/1471-2458-12-99.

[29] Cheah, Y. K. 2013. "Determinants of the Demand for Using Preventive Medical Care among Adults in Penang, Malaysia.” The Malaysian Journal of Medical Sciences. MJMS $20 \quad$ (1): 46-55. http://europepmc.org/abstract/pmc/pmc3629883 Accessed 15th may 2017.

[30] Udigwe, G. O. 2006. "Knowledge, Attitudes and Practices of Cervical Cancer Screening (Pap Smear) among Female Nurses in Nnewi, South Eastern, Nigeria.” Nigerian Journal of Clinical Practice 9 (1): 40-3. 